\title{
Biocompatibility of New High-Entropy Alloys with Non-Cytotoxic Elements
}

Pedro Socorro-Perdomo $^{1}$, Nestor Florido-Suarez ${ }^{1}$, Ionelia Voiculescu ${ }^{2}$ and Julia Mirza-Rosca ${ }^{1}$

${ }^{1}$ University of Las Palmas de Gran Canaria, United States, ${ }^{2}$ Politehnica University of Bucharest, United States

Introduction

In the 1980s, the possibility of creating alloys by combining different elements or materials began to be developed theoretically. By changing the proportion of each of the elements that form part of the alloy, the properties of the alloy can be improved, making the different components "work as a team", giving rise to materials with better behavior against corrosion attacks, others against impacts, etc. [1][2]. This theoretical development gave rise to the idea of high entropy alloys (HEA). In 1995, Professor Jen-Wei Yeh, National Tsing Hua University, Hsinchu, Taiwan, suggested making alloys using five or more different metals in similar proportions to make them alloys with many major elements. The name High Entropy Alloys is in fact due to the fact that the high stability of these alloys is because of their high entropy, which increases with the number of elements used for their preparation and composition. In parallel, Brian Cantor, from the University of Bradford, together with his research team, was also working with high entropy alloys [3]. It was Professor Yeh who gave the name to this type of alloys, but Brian Cantor, despite not referring to them with that terminology when working with them, developed a high-entropy alloy using the same number of atoms of each element, which has been and is the basis of the studies carried out since then within this field of research. In this work, the behavior of two HEA (High Entropy Alloys) of different composition, in simulated body fluid, is studied in order to determine whether these alloys are suitable for use in the field of medical prosthesis and implants.

\section{Experimental}

The studied materials, namely HEA 1 and HEA2, have the following composition:

HEA 1: $20.45 \% \mathrm{Mo}, 32.45 \% \mathrm{Ta}, 12.67 \% \mathrm{Ti}, 18.97 \% \mathrm{Zr}$ and $15.46 \% \mathrm{Fe}$

HEA 2: $17.32 \% \mathrm{Mo}, 38.95 \% \mathrm{Ta}, 13.21 \% \mathrm{Ti}, 17.45 \% \mathrm{Zr}$ and $13.07 \% \mathrm{Nb}$.

In order to characterize the properties of these two alloys, different electrochemical methods were used. Electrochemical Impedance Spectroscopy and the analysis of the spectra was carried out by fitting different equivalent circuits to the experimental data [4], [5]. The spectroscopy impedance results were correlated with the microstructure which was characterized by Optical Microscopy, Scanning Electron Microscopy and Energy-dispersive X-ray Spectroscopy.

The electrochemical studies were performed in Ringer solution, an isotonic solution typically composed of potassium chloride, sodium bicarbonate, calcium chloride and sodium chloride. A solution that resembles the plasma contained in the blood of human beings and is therefore useful for tests such as those carried out in this study, where the aim is to work by simulating as a working environment, body fluids, which help the body to balance its $\mathrm{pH}$, the activation of muscles and nervous systems.

Results and discussion

The microstructures of the studied alloys are presented in Fig.1 and Fig.2.

Both HEA 1 and HEA 2 have an apparently homogeneous structure and the presence of dendrites due to the rapid cooling of these in the copper base where they have been manufactured can be clearly observed. 
From the electrochemical tests we can say that HEA 1 has a lower corrosion potential than HEA 2, which means that HEA 1 is more susceptible to corrosion than HEA 2.

On the other hand, HEA 1 shows a pitting potential of $0.700 \mathrm{~V}$ and a repassivation potential of $0.331 \mathrm{~V}$ while HEA 2 is the most resistant to this type of corrosion, showing no damage during the test.

\section{Conclusions}

Both alloys exhibit spontaneous passivation with a low passive current density, low corrosion rate and high electrochemical impedance in Ringer solution, indicating a better bio-corrosion resistance than Ti6Al4V used nowadays. The good biocompatibility of the two alloys in simulated body fluid can be mainly attributed to the non-cytotoxic surface film and to the high corrosion resistance of the studied alloys. The surface film is noncytotoxic because is consisted of oxides of high biocompatible elements as $\mathrm{Nb}$, Ta and $\mathrm{Ti}$. The high corrosion resistance leads to a less release of corrosion products during service life. Therefore, all the results further demonstrated the potential of the analyzed high-entropy alloys for biomedical applications.

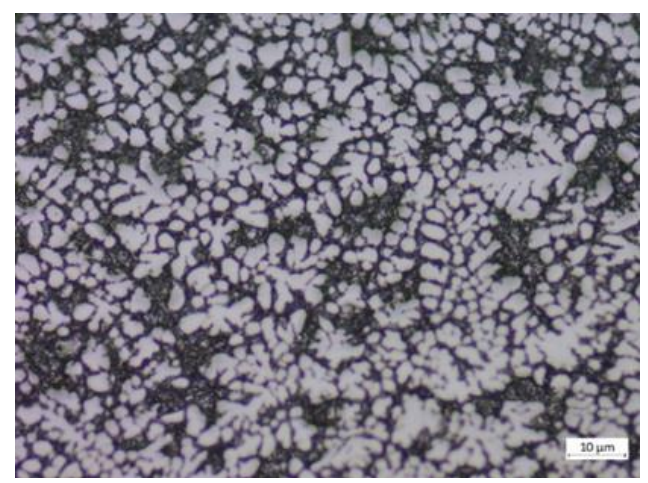

Figure 1. Microstructure of HEA1

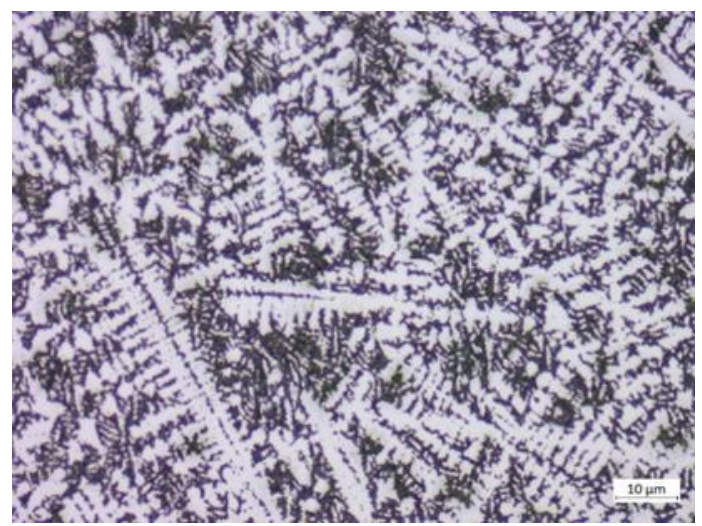

Figure 2. Microstructure of HEA2

\section{References}

[1] M. L. Rios, V. L. Baldevenites, I. Voiculescu, and J. M. Rosca, "AlCoCrFeNi High Entropy Alloys as Possible Nuclear Materials," Microsc. Microanal., 2020, doi: 10.1017/s1431927620014555.

[2] M. López Ríos et al., "Effects of nickel content on the microstructure, microhardness and corrosion behavior of high-entropy AlCoCrFeNix alloys," Sci. Rep., vol. 10, no. 1, pp. 1-11, 2020, doi: 10.1038/s41598020-78108-5.

[3] Y. F. Ye, Q. Wang, J. Lu, C. T. Liu, and Y. Yang, "High-entropy alloy: challenges and prospects," Materials Today, vol. 19, no. 6. Elsevier B.V., pp. 349-362, Jul. 01, 2016, doi: 10.1016/j.mattod.2015.11.026. 
[4] N. Ibriş and J. C. Mirza Rosca, "EIS study of Ti and its alloys in biological media," J. Electroanal. Chem., 2002, doi: 10.1016/S0022-0728(02)00814-8.

[5] D. Mareci, G. Ungureanu, N. Aelenei, R. Chelariu, and J. C. M. Rosca, "Eis diagnosis of some dental alloys in artificial saliva," Environ. Eng. Manag. J., 2007, doi: 10.30638/eemj.2007.034. 